\title{
Investigation of Industrial Polyurethane Foams Modified with Antimicrobial Copper Nanoparticles
}

\author{
Maria Chiara Sportelli ${ }^{1}$, Rosaria Anna Picca ${ }^{1}$, Roberto Ronco ${ }^{1}$, Elisabetta Bonerba ${ }^{2}$, \\ Giuseppina Tantillo ${ }^{2}$, Mauro Pollini ${ }^{3}$, Alessandro Sannino ${ }^{3}$, Antonio Valentini ${ }^{4}$, \\ Tommaso R.I. Cataldi ${ }^{1}$ and Nicola Cioffi ${ }^{1, *}$
}

1 Dipartimento di Chimica, Università Degli Studi di Bari “Aldo Moro”, via E. Orabona 4, Bari (BA) 70126, Italy; maria.sportelli@uniba.it (M.C.S.); rosaria.picca@uniba.it (R.A.P.); robertoronco1@libero.it (R.R.); tommaso.cataldi@uniba.it (T.R.I.C.)

2 Dipartimento di Medicina Veterinaria, Università Degli Studi di Bari “Aldo Moro”, St.da P.le per Casamassima Km 3, Valenzano (BA) 70010, Italy; elisabetta.bonerba@uniba.it (E.B.); giuseppina.tantillo@uniba.it (G.T.)

3 Dipartimento di Ingegneria dell'Innovazione, Università del Salento, via per Monteroni, Lecce (LE) 73100, Italy; mauro.pollini@unisalento.it (M.P.); alessandro.sannino@unisalento.it (A.S.)

4 Dipartimento Interateneo di Fisica, Università Degli Studi di Bari “Aldo Moro”, via Amendola 173, Bari (BA) 70126, Italy; antonio.valentini@uniba.it

* Correspondence: nicola.cioffi@uniba.it; Tel.: +39-080-544-2020

Academic Editor: Carla Renata Arciola

Received: 22 April 2016; Accepted: 29 June 2016; Published: 7 July 2016

\begin{abstract}
Antimicrobial copper nanoparticles (CuNPs) were electrosynthetized and applied to the controlled impregnation of industrial polyurethane foams used as padding in the textile production or as filters for air conditioning systems. CuNP-modified materials were investigated and characterized morphologically and spectroscopically, by means of Transmission Electron Microscopy (TEM), and X-ray Photoelectron Spectroscopy (XPS). The release of copper ions in solution was studied by Electro-Thermal Atomic Absorption Spectroscopy (ETAAS). Finally, the antimicrobial activity of freshly prepared, as well as aged samples-stored for two months-was demonstrated towards different target microorganisms.
\end{abstract}

Keywords: copper nanoparticle; polyurethane foam; ETAAS; XPS; nanoantimicrobials

\section{Introduction}

Application of nanotechnology in the textile industry is practiced with two main purposes. The first one aims at the improvement of the textile performance: fibers modified by nanopowders, or carbon nanotubes (CNTs), generally possess higher mechanical resistance in respect with untreated ones [1]. The second purpose deals with the development of multifunctional textiles, i.e., antimicrobial [2], anti-stain [3], water repellent [4,5], anti-static [6-8], and self-cleaning ones [9]. Cotton, linen, silk and wool are well-known natural fibers and padding materials, breathable and resistant [10]. However, they are easily degraded by many microorganisms, like spores, molds and bacteria [11,12]. Special finishes, however, can provide them protection from biodegradation: nanotechnology offers a good range of effective tools to protect fabrics from bacterial contamination [2]. During the last century, the discovery and the growing production of polymer-based artificial fibers and paddings completely eliminated the problems related to biodegradation. Polyurethane foams play a fundamental role in the production of seats in the automotive sector, of filters for the conditioning and treatment of air and water, and so on. However, in all these fields, prevention of bacterial adhesion and/or proliferation is extremely important. Metal and metal oxide nanoparticles (NPs), specifically $\mathrm{Cu}$ and its oxides, have been already used for this purpose $[13,14]$. Natural fiber modification with copper is rather 
prevalent and different reports are present in literature on this topic, especially for the treatment of cotton fabrics [14]. Most of them deal with their $\mathrm{CuO}$ or $\mathrm{Cu}_{2} \mathrm{O}$ functionalization [15-23], while the use of elemental $\mathrm{Cu}$ is reported less frequently [24,25]. $\mathrm{Cu}(0)$, in fact, easily undergoes oxidation processes unless suitable stabilizing agents are used. Nevertheless, modification of artificial polymers by nanostructured $\mathrm{Cu}$ is less diffused, and it is generally achieved by adding a copper-containing additive to the polymers during the master batch preparation stage [26-29]. Silicone fibers [30], polyester [26,31,32], and nylon [33] have been successfully modified by both nanostructured $\mathrm{CuO}$ and $\mathrm{Cu}$. Polyurethane (PU) has been modified by different types of inorganic clusters, such as Ag [34-44], CNTs (carbon nanotubes) [45], Zn-Ag bimetallic particles [46], tourmaline [47,48], silica [49] and $\mathrm{ZnO}$ [50]. Ag is nowadays one of the preferred additives to confer antimicrobial properties to both natural and synthetic fibers, being well known its antiseptic effect against a wide range of microorganisms. Ag-modified PU foams or fibers are fairly common: in fact, silver is able to confer antimicrobial properties and to improve polymer mechanical and rheological properties [43]. However, to the best of our knowledge, only a few reports are present in the literature about the modification of polyurethanes with antimicrobial CuNPs [51-53].

Here we report on polyurethane foams modified with colloidal CuNPs that were electrochemically synthesized by means of the so-called sacrificial anode electrolysis (SAE) technique [54]. Post-production functionalization of industrial polyurethane foams was carried out by their impregnation in diluted CuNP colloids. Samples were morphologically and spectroscopically investigated and characterized. Their antimicrobial activity was tested towards three model microorganisms (Staphylococcus aureus, Escherichia coli and Kluyveromyces marxianus), demonstrating CuNPs capability of strongly inhibiting bacterial growth and proliferation.

\section{Results and Discussion}

\subsection{Synthesis and Characterization of $\mathrm{CuNPs}$}

CuNPs, used as additives of industrial polyurethane foams, were prepared by sacrificial anode electrolysis as described in the experimental section. Cu concentration in the stock colloidal solution was obtained by differential weighing of working and counter electrodes: it resulted equal to $0.31 \pm 0.05 \mathrm{M}$ in as-synthesized Cu-nanocolloids. TOAC (tetraoctylammonium chloride) was chosen as stabilizing agent, due to the high reaction yield of TOAC-driven syntheses $(85 \% \pm 5 \%)$, excellent morphological control, and lasting storage times of the colloid up to months; there is only the need to avoid air exposure and thermal shocks. Moreover, TOAC octyl chains confer lipophilicity to metal NPs, which become scarcely soluble in water [55]. This attribute can be proficiently used to promote PU impregnation with CuNPs. With regard to pristine $\mathrm{Cu}$-nanocolloids, the high degree of stabilization provided by TOAC capping agent was demonstrated by the TEM micrograph reported in Figure $1 \mathrm{a}$. The electrochemical process resulted in a NP population with a single mode and narrow diameter dispersion, centered at $2.6 \mathrm{~nm}(\sigma \leqslant 0.5 \mathrm{~nm})$, as shown in the size distribution histogram of Figure $1 \mathrm{~b}$.
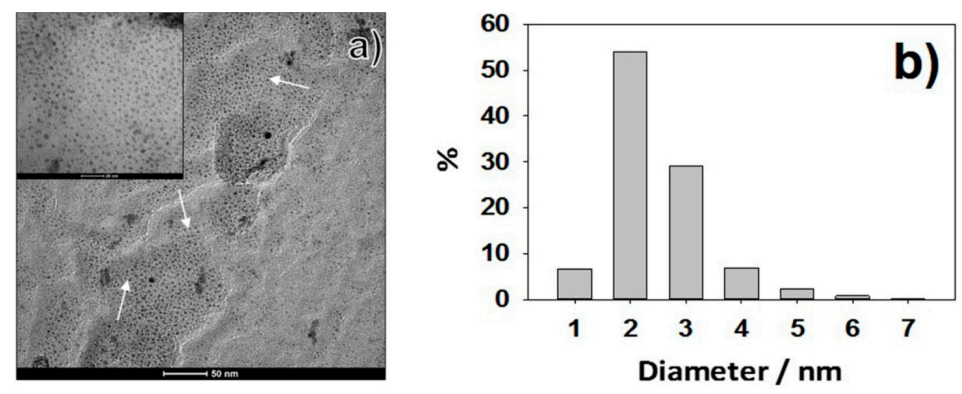

Figure 1. (a) Transmission Electron Microscopy (TEM) micrographs of CuNPs (highlighted by arrows) synthesized by sacrificial anode electrolysis. A micrograph at higher magnification is reported as insert; (b) Size distribution histogram of as synthesized CuNPs. 


\subsection{Adsorption of Industrial Polyurethane Foams with $\mathrm{CuNPs}$}

PU samples were treated with CuNP-colloids as reported in Section 3.3. Two different types of polyurethane foam were used. For clarity of presentation, they were labeled as follows:

- Sample A: green foam, with large and irregular pores, used as filling material for mattresses (density: $25 \mathrm{~kg} / \mathrm{m}^{3}$, density tolerance $\pm 5 \%$ );

- Sample B: white foam, with small and regular pores, used in the automotive industry (density: $21 \mathrm{~kg} / \mathrm{m}^{3}$, density tolerance $\pm 5 \%$ ).

Adsorption efficiency was tested by weighing each sample before and after the modification process. Both samples showed an average weight increase equal to $8.2 \pm 0.3 \mathrm{mg}$ for type A PU and $7.8 \pm 0.2 \mathrm{mg}$ for type B PU, respectively. Pristine and treated foams were subjected to optical microscopy examination. This aimed at ascertaining that the impregnation process did not alter PU pores morphology and/or dimension. Typical optical micrographs are reported in Figure 2. A bigger and more dispersed pore size was observed for pristine samples A (Figure 2a,c,e), while pristine samples B were characterized by a more regular porous structure (Figure $2 \mathrm{~b}, \mathrm{~d}, \mathrm{f}$ ). These features remained unaffected after the impregnation process (Figure $2 \mathrm{~g}, \mathrm{~h}$ ).

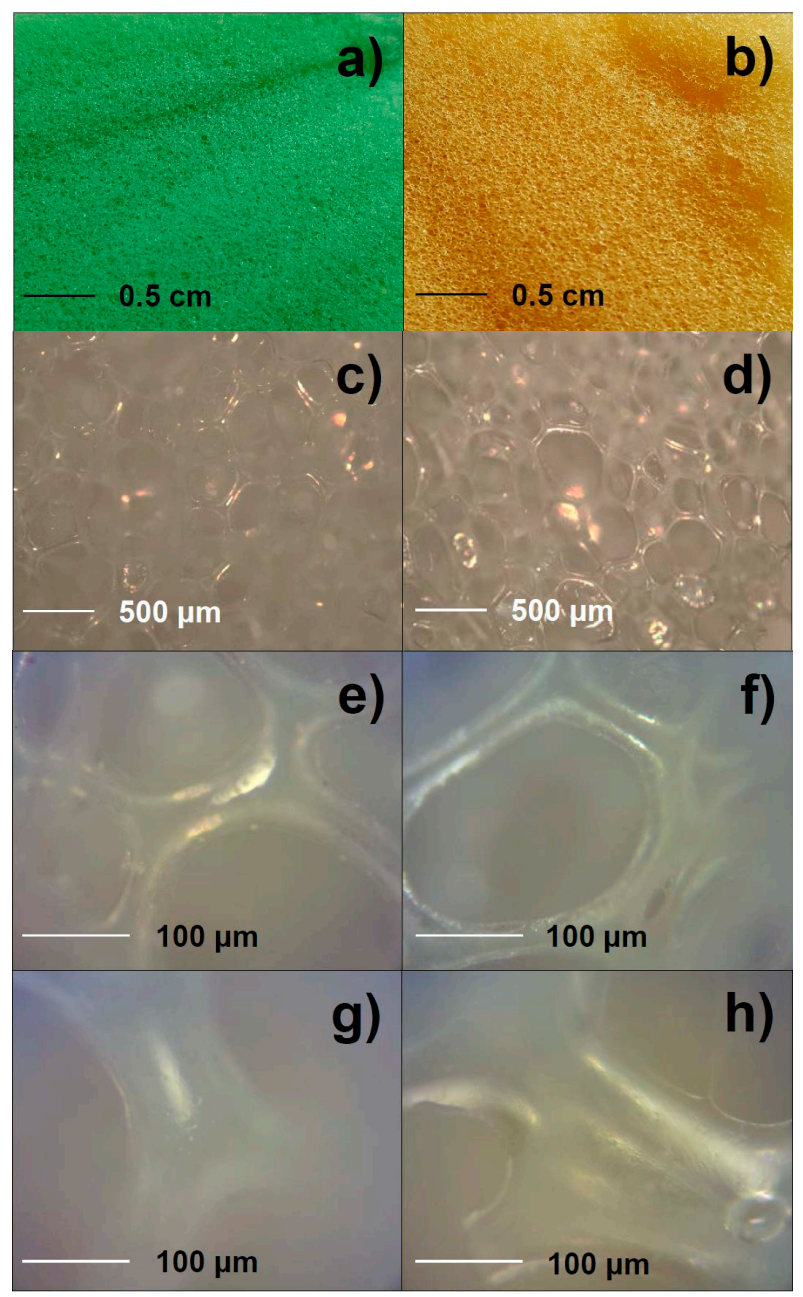

Figure 2. Photographs of (a) type A and (b) type B pristine polyurethane (PU) foams. Optical micrographs of pristine and Cu-treated foams; (c) Low magnification-Pristine type A foam; (d) Low magnification-Pristine type B foam; (e) High magnification-Pristine type A foam; (f) High magnification-Pristine type B foam; (g) 1:1000 Cu-modified type A foam; (h) 1:1000 Cu-modified type B foam. 


\subsection{Surface Chemical Characterization of CuNP-Modified Industrial Polyurethane Foams}

In order to assess the surface chemical composition of CuNP-modified polyurethane foams, XPS (X-ray photoelectron spectroscopy) analyses were performed. Both A and B PU samples were studied before and after treatment with CuNPs colloids, purposely suspension dilute 100- and 1000-fold with pure solvent. Data of Table 1 show that carbon and oxygen were the most abundant elements on the analyzed surfaces, as expected for an oxygenated polymer dispersing matrix modified by low amounts of CuNPs.

Table 1. Surface elemental composition estimated by X-ray photoelectron spectroscopy (XPS) of fresh samples A and B, treated with CuNPs. Error is expressed as the larger value between the error associated to a single quantification $(0.2 \%$ for copper, $0.5 \%$ for other elements) and one standard deviation, calculated on at least three replicate analyses. Data about pristine samples are reported for comparison.

\begin{tabular}{|c|c|c|c|c|c|c|}
\hline \multirow[b]{2}{*}{ Element } & \multicolumn{3}{|c|}{ Sample A } & \multicolumn{3}{|c|}{ Sample B } \\
\hline & Pristine & $\begin{array}{c}\text { PU/CuNPs } \\
(1: 100)\end{array}$ & $\begin{array}{c}\text { PU/CuNPs } \\
(1: 1000)\end{array}$ & Pristine & $\begin{array}{c}\text { PU/CuNPs } \\
(1: 100)\end{array}$ & $\begin{array}{c}\text { PU/CuNPs } \\
(1: 1000)\end{array}$ \\
\hline $\mathrm{Cu}$ & $<0.2 \%$ & $1.3 \pm 0.2$ & $0.8 \pm 0.2$ & $<0.2 \%$ & $0.5 \pm 0.2$ & $0.3 \pm 0.2$ \\
\hline $\mathrm{C}$ & $73.7 \pm 0.5$ & $76.9 \pm 0.5$ & $79 \pm 3$ & $72.6 \pm 0.5$ & $68.4 \pm 0.5$ & $67.5 \pm 0.5$ \\
\hline $\mathbf{N}$ & $1.6 \pm 0.5$ & $1.7 \pm 0.5$ & $1.3 \pm 0.5$ & $1.6 \pm 0.5$ & $1.6 \pm 0.5$ & $2.8 \pm 0.5$ \\
\hline O & $23.3 \pm 0.5$ & $18.5 \pm 0.5$ & $18 \pm 3$ & $20.7 \pm 0.5$ & $24.4 \pm 0.5$ & $23.7 \pm 0.5$ \\
\hline $\mathrm{Si}$ & $1.4 \pm 0.5$ & $1.6 \pm 0.5$ & $0.9 \pm 0.5$ & $4.5 \pm 0.5$ & $5.1 \pm 0.5$ & $5.7 \pm 0.5$ \\
\hline $\mathrm{Cl}$ & - & $<0.5$ & $<0.5$ & - & $<0.5$ & $<0.5$ \\
\hline $\mathrm{Ca}$ & - & - & - & $0.6 \pm 0.5$ & $<0.5$ & $<0.5$ \\
\hline
\end{tabular}

$\mathrm{Cu}$ traces could be qualitatively observed on pristine samples, although they were below the XPS limit of quantification. This evidence is reasonable, considering that extrusion of PU foams is performed using copper dyes. Small amounts of $\mathrm{Si}$ were also identified: this element is characteristic of PU and PU-based goods production processes [56]. Presence of nitrogen could be attributed to both TOAC (when present) and polymeric backbone. It is also important to point up how $\mathrm{Cu}$-modified samples $\mathrm{A}$ had in general a higher $\mathrm{Cu}$ atomic \%, compared to homologous composites B (e.g., composites obtained by impregnation with the same CuNP dilution). This might be due to the presence of larger pores, which allowed CuNPs to better penetrate into the bulk material. Chlorine is due to the presence of CuNP stabilizing agent (i.e., TOAC), while traces of calcium observed in samples B were considered as a contamination coming from PU industrial production processes.

$X P$ high-resolution (HR) regions were also investigated, in order to obtain detailed information about PU and CuNPs chemical speciation. HR XP C1s spectra of pristine and treated PU foams were made of three main components. As an example, Table 2 resumes data obtained on samples A in terms of peak position (expressed as Binding Energy-BE-values), relative abundance, and signal attribution.

Table 2. Attributions of C1s chemical environments identified on type A pristine and Cu-modified PU foams; relative abundance \% of each signal component is reported for comparison. Error is expressed as one standard deviation, calculated on at least three replicate analyses.

\begin{tabular}{cccc}
\hline Sample & BE $(\mathbf{e V})$ & Attribution & Relative Abundance \% \\
\hline \multirow{3}{*}{ Pristine } & $284.8 \pm 0.1$ & $\mathrm{C}-\mathrm{C}$ & $43 \pm 2$ \\
& $286.4 \pm 0.2$ & $\mathrm{C}-\mathrm{O}, \mathrm{C}-\mathrm{N}$ & $55.8 \pm 1.3$ \\
& $289.0 \pm 0.2$ & $\mathrm{HN}-\mathrm{C}=\mathrm{O}$ & $1.2 \pm 0.8$ \\
\hline \multirow{2}{*}{ PU/CuNPs (1:100) } & $284.8 \pm 0.1$ & $\mathrm{C}-\mathrm{C}$ & $55 \pm 3$ \\
& $286.4 \pm 0.2$ & $\mathrm{C}-\mathrm{O}, \mathrm{C}-\mathrm{N}$ & $42 \pm 2$ \\
& $288.8 \pm 0.2$ & $\mathrm{HN}-\mathrm{C}=\mathrm{O}$ & $3.0 \pm 1.3$ \\
\hline
\end{tabular}


All components are in agreement with those expected for PU [57,58]. On Cu-modified foams, a higher relative percentage of aliphatic $\mathrm{C}-\mathrm{C}$ moieties was observed. This could be explained considering the presence of octyl- alkyl chains from TOAC. HR XP N1s spectra were characterized by a single component in all cases, centered at $400.0 \pm 0.2 \mathrm{eV}$, compatible with PU urethane functionalities [58]. Typical Cu2 $\mathrm{p}_{3 / 2} \mathrm{XP}$ spectra for fresh and aged samples are reported in Figure 3. Soon after sample preparation (Figure 3a), a single signal falling at $933.2 \pm 0.2 \mathrm{eV}$ was present. This peak can be ascribed both to nanodispersed $\mathrm{Cu}$ at zero oxidation state [58-60] and/or to cuprous species [57,58]. The absence of $\mathrm{Cu}$ (II) moieties was confirmed by the lack of photoelectronic signals in the region centered at about $934.0 \pm 0.2 \mathrm{eV}$ and the shake-up features between 941.0 and $948.0 \mathrm{eV}$, as well [57]. CuNPs undergo a certain surface oxidation, as a function of the aging time. This phenomenon led to the formation of cupric moieties onto modified PU foams. Cu2 $\mathrm{p}_{3 / 2} \mathrm{XP}$ high-resolution region showed, for aged samples (Figure $3 \mathrm{~b}$ ), the presence of a second signal component, at higher binding energy values $(934.4 \pm 0.3 \mathrm{eV})$, ascribable to $\mathrm{Cu}(\mathrm{II})$ moieties. Shake-up bands were, in this case, barely visible, due to the very high signal-to-noise ratio.
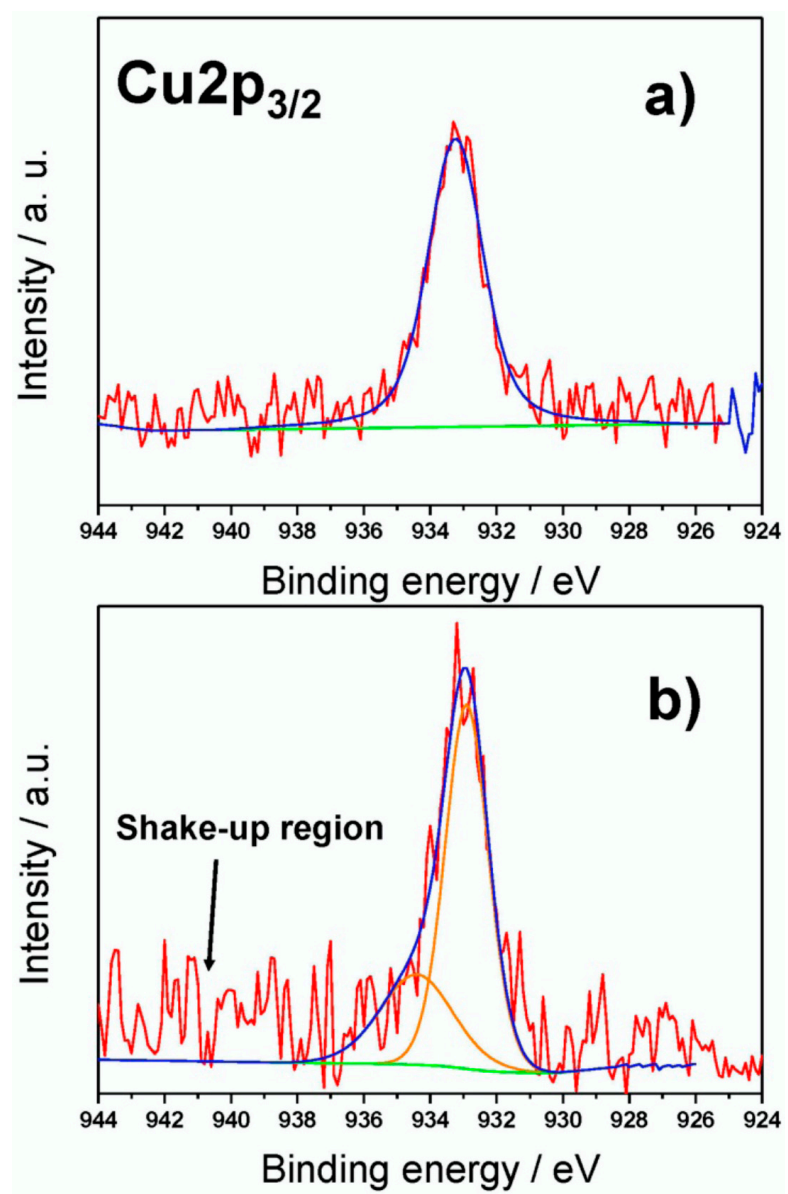

Figure 3. Typical Cu2 $\mathrm{p}_{3 / 2} \mathrm{X}$-ray photoelectron (XP) high-resolution spectra of fresh (a); and aged (b) CuNP-modified polyurethane foams.

\subsection{Kinetics of Copper Release from CuNP-Modified Industrial Polyurethane Foams}

CuNP-modified PUs were exposed to a physiological saline solution in order to mimic a possible interaction and ionic release of nanocomposites to model contact media. Experiments were carried out on both freshly prepared and aged samples, which were stored in air for 60 days. The kinetics of $\mathrm{Cu}$ release, relative to all the analyzed samples are shown in Figure 4 . The experimental data could be interpolated, in all cases, by a pseudo-first order kinetic model. 


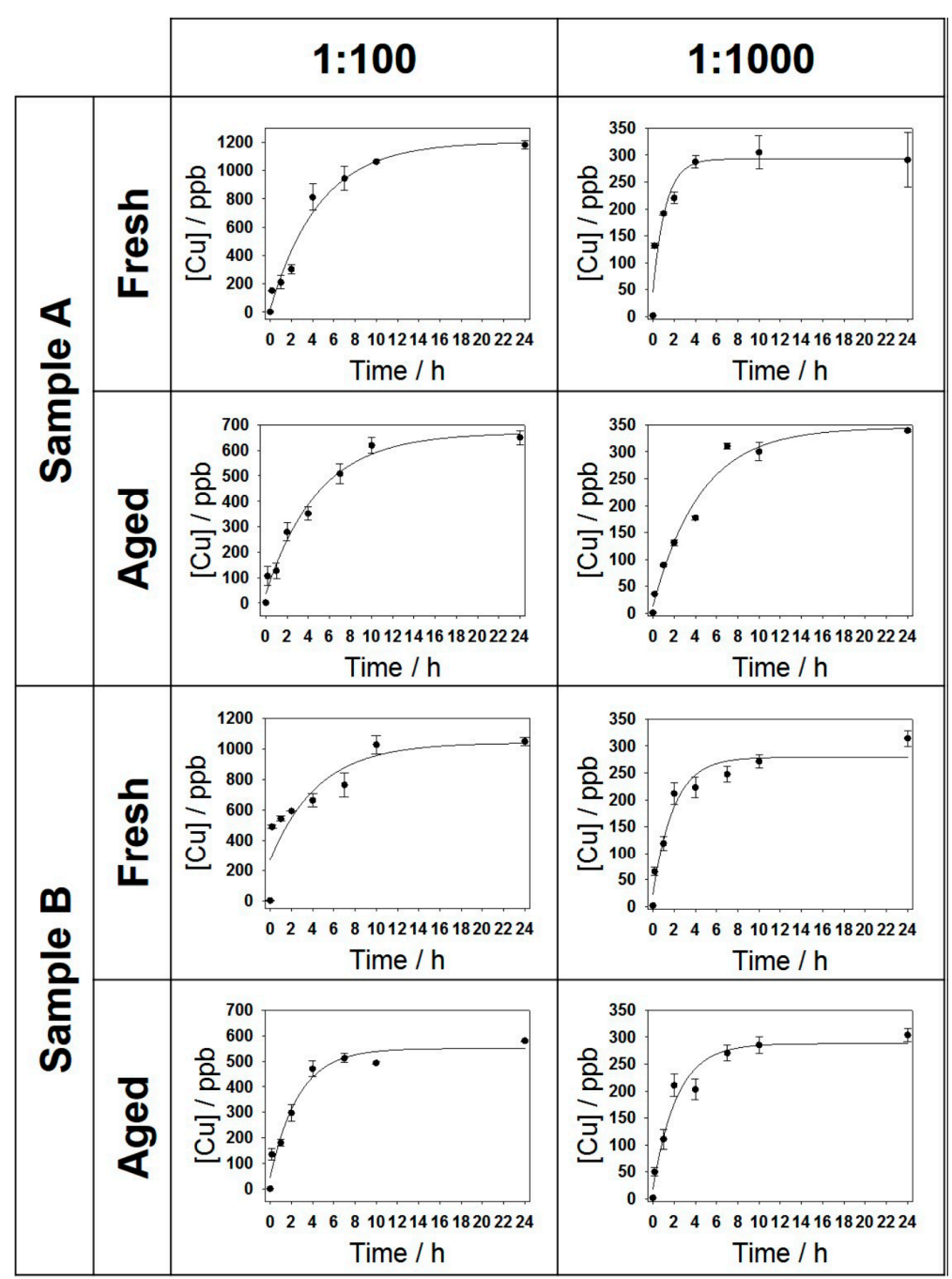

Figure 4. Copper release in physiologic solution from CuNP-modified polyurethane foams, as a function of the incubation time. Different columns are relevant to different CuNP concentrations in the impregnation baths, giving rise to different $\mathrm{Cu}$ surface abundance on the composite. Different rows are relevant to composites obtained by different polyurethane batches or to differently aged samples.

From the analysis of all the curves, it was found that part of the $\mathrm{Cu}$ ion release in solution was quite fast in the first ten minutes. This is reasonably due to the presence of readily soluble $\mathrm{Cu}$ species (such as residual cuprous salts) on the surface of CuNPs. It was also evident, in all cases, that $\mathrm{Cu}$ concentration progressively grew as a function of time up to a plateau value. The extent of the latter varied according to the concentration of the impregnation bath, and as a function of the aging time, too. In both samples, in fact, a higher mean plateau value was registered for PU foams treated with 1:100 colloidal dilutions, which had the higher surface $\mathrm{Cu}$ concentration. The larger pore size of composites based on A-type PU might explain the slightly higher and faster $\mathrm{Cu}$ release recorded for materials treated with 1:100 CuNPs dilution, due to a possible easier accessibility of the physiological solution within samples A. In principle, a larger pore size should allow a deeper and easier penetration of physiological solution within the foam. Moreover, for both samples A and B, aging resulted in a considerable decrease of the $\mathrm{Cu}$ release. A tentative interpretation of this phenomenon was that surfactant could, over time, segregate [61-63] and partially occlude PU pores, enhancing the surface hydrophobicity of the composite and partially limiting the accessibility of the physiological solution within them. The average values of plateau $\mathrm{Cu}$ concentrations, $[\mathrm{Cu}]^{0}$, and kinetic constants for all samples are summarized in Table 3. 
Table 3. Average values of plateau $\mathrm{Cu}$ concentrations and kinetic constants for samples $\mathrm{A}$ and B. Data about fresh and aged samples are reported. The error is expressed as the largest value between the standard deviation relevant to the repeated measurements and the error associated to individual quantifications.

\begin{tabular}{|c|c|c|c|c|c|c|c|}
\hline \multirow{2}{*}{ Sample } & \multirow{2}{*}{$\begin{array}{c}\text { CuNPs } \\
\text { Dilution }\end{array}$} & \multicolumn{2}{|c|}{ Plateau $[\mathrm{Cu}] / \mathrm{ppb}$} & \multicolumn{2}{|c|}{ Kinetic Constant $/ \mathrm{h}^{-1}$} & \multicolumn{2}{|c|}{$[\mathrm{Cu}]^{0} / \mathrm{ppb}$} \\
\hline & & Fresh & Aged & Fresh & Aged & Fresh & Aged \\
\hline Sample A & $\begin{array}{c}1: 100 \\
1: 1000\end{array}$ & $\begin{array}{c}1200 \pm 90 \\
300 \pm 40\end{array}$ & $\begin{array}{l}670 \pm 40 \\
330 \pm 20\end{array}$ & $\begin{array}{c}0.20 \pm 0.04 \\
0.8 \pm 0.3\end{array}$ & $\begin{array}{l}0.20 \pm 0.04 \\
0.20 \pm 0.04\end{array}$ & $\begin{array}{c}0 \\
50 \pm 30\end{array}$ & $40 \pm \frac{30}{0}$ \\
\hline Sample B & $\begin{array}{c}1: 100 \\
1: 1000\end{array}$ & $\begin{array}{c}1100 \pm 200 \\
260 \pm 30\end{array}$ & $\begin{array}{l}550 \pm 40 \\
270 \pm 20\end{array}$ & $\begin{array}{l}0.2 \pm 0.1 \\
0.5 \pm 0.1\end{array}$ & $\begin{array}{c}0.40 \pm 0.09 \\
0.4 \pm 0.1\end{array}$ & $\begin{array}{c}300 \pm 100 \\
30 \pm 20\end{array}$ & $\begin{array}{l}40 \pm 30 \\
20 \pm 20\end{array}$ \\
\hline
\end{tabular}

\subsection{Antimicrobial Tests}

The antimicrobial properties of freshly prepared Cu-polyurethane composites were evaluated in preliminary tests on three target microorganisms selected based on microorganisms characteristics (Gram-positive, Gram-negative, yeasts) to demonstrate the broad-spectrum of NP antimicrobial activity. The suitable dilution tested was obtained taking into account the pathogenic role of microorganisms (mainly S. aureus and E. coli), the spread and persistence of S. aureus on the surfaces, the assessment of $E$. coli as hygiene requirement, and the environment ubiquity of K. marxianus. Culture broths were diluted by different factors, based on the different characteristics of the microorganisms ( $10^{7}$ for S. aureus, $10^{5}$ for E. coli and $10^{3}$ for K. marxianus), and then they were left in contact for fixed times with different samples in order to discriminate the biocidal/biostatic effects of pristine PU foams, electrolytic solution, and CuNP-treated materials. In any sample, after a contact time of $24 \mathrm{~h}$, the residual microorganism growth was quantified by counting the number of colony forming units (CFU). The results are reported in Table 4. As expected, blank experiments on pristine PU foams did not show any biostatic action, whereas control samples treated with $0.1 \mathrm{M}$ TOAC solution in Acetonitrile/tetrahydrofuran (ACN/THF) $1 / 3_{\mathrm{v} / \mathrm{v}}$ mixture produced a strong inhibition effect against $S$. aureus, causing a complete inhibition of the bacterial growth. This is a reasonable result, since TOAC salt belongs to the class of common quaternary ammonium disinfectants. Using $\mathrm{Cu}$-modified polyurethanes induced a marked growth inhibition even in the case of microorganisms such as E. coli, that did not show any sensitivity to TOAC-impregnated PU. Finally, comparing the activity of composites treated by colloidal dilutions of 1:100 and 1:1000, it can be concluded that a higher CuNP loading was generally correlated to a higher concentration of released ions, hence in an increased inhibition of colony growth. In some experiments apparent discrepancies between ionic release and bioactivity were observed and attributed to limited reproducibility of the investigated biological systems.

Table 4. Number of colony forming units (CFU) for the three target microorganisms, exposed to different samples for $24 \mathrm{~h}$ as described in the experimental section. Error on CFU counts is \pm 5 in the last digit.

\begin{tabular}{|c|c|c|c|c|}
\hline \multicolumn{2}{|c|}{ Sample } & S. aureus/CFU & E. coli/CFU & K. marxianus/CFU \\
\hline \multirow{4}{*}{ Sample A } & \multirow{4}{*}{$\begin{array}{c}\mathrm{PU} \\
\mathrm{PU}+0.1 \mathrm{M} \text { TOAC } \\
\text { solution } \\
\mathrm{PU}+1: 1000 \mathrm{CuNPs} \\
\mathrm{PU}+1: 100 \mathrm{CuNPs}\end{array}$} & $\mathrm{U}^{\mathrm{a}}$ & $\mathrm{U}$ & $\mathrm{U}$ \\
\hline & & 0 & $\mathrm{U}$ & $\mathrm{U}$ \\
\hline & & 0 & 0 & 30 \\
\hline & & 0 & 0 & 25 \\
\hline \multirow{4}{*}{ Sample B } & \multirow{4}{*}{$\begin{array}{c}\mathrm{PU} \\
\mathrm{PU}+0.1 \mathrm{M} \text { TOAC } \\
\text { solution } \\
\mathrm{PU}+1: 1000 \mathrm{CuNPs} \\
\mathrm{PU}+1: 100 \mathrm{CuNPs}\end{array}$} & $\mathrm{U}$ & $\mathrm{U}$ & $\mathrm{U}$ \\
\hline & & 2 & $\mathrm{U}$ & $\mathrm{U}$ \\
\hline & & $\mathrm{U}$ & 72 & $\mathrm{U}$ \\
\hline & & 0 & 0 & $\mathrm{U}$ \\
\hline
\end{tabular}




\section{Materials and Methods}

\subsection{Materials}

Copper (0.5 mm thick, 99.99+\%) and platinum sheets (0.25 mm thick, 99.999\%) were purchased from Goodfellow Ltd. (Cambridge, UK) and cut into $2 \times 1 \mathrm{~cm}$ pieces. Acetonitrile (ACN, anhydrous, 99.8\%), tetrahydrofuran (THF, anhydrous, $\geqslant 99.9 \%$, inhibitor-free), and tetraoctylammonium chloride (TOAC, AT reagent, $\geqslant 97.0 \%$ ), were purchased from Sigma Aldrich (Milan, Italy). Aluminum Oxide (purum p.a., 99.7\%), for the mechanical polishing of metallic sheets, was from Fluka Chemicals (Milan, Italy). Polyurethane foams were obtained from the industrial partner ME.RES. Meridionale Resine S.r.L (Avellino, Italy).

Escherichia coli ATCC 25922, Staphylococcus aureus FDA 209P (MSSA, with methicillin resistance $\left.0.125 \mu \mathrm{g} \cdot \mathrm{mL}^{-1}\right)$, and Kluyveromyces marxianus CBS 608, selected as target microorganisms for biological tests, were obtained from BioMérieux Italia S.p.A. (Florence, Italy), and reconstituted in nutrient broth (Agar Oxoid), purchased from Bio-Chemia (Bari, Italy), as the Plate Count Agar culture medium.

\subsection{Electrochemical Synthesis of $\mathrm{CuNPS}$}

The electrochemical synthesis of CuNPs was carried out in a three-electrode cell equipped with a $\mathrm{Cu}$ working electrode and an $\mathrm{Ag} / \mathrm{AgNO}_{3} 0.1 \mathrm{M}$ in $\mathrm{ACN}$ reference electrode. The counter electrode was a $\mathrm{Pt}$ sheet. The electrolytic solution was composed of $0.1 \mathrm{M}$ TOAC dissolved in an ACN/THF 1/3 mixture. The electrosynthesis was carried out in nitrogen atmosphere, potentiostatically, $(+1.5 \mathrm{~V}$ vs. reference) for $6 \mathrm{~h}$, under vigorous stirring at room temperature, with a CH1140b potentiostat-galvanostat (CH Instruments, Austin, TX, USA). Other electrochemical parameters such as electrodes pretreatment, electrolysis cell, process details, etc. were similar to what reported in previous works [61-63].

\subsection{Modification of Industrial Polyurethane Foams with CuNPs}

Cubic samples, of approximately $1 \mathrm{~cm}^{3}$, and weighing about $100 \mathrm{mg}$, were obtained cutting the as-received materials.

After ascertaining the resistance of each sample towards the solvents used for the electrosynthesis, each material was treated with CuNPs by immersion in $5 \mathrm{~mL}$ of diluted colloids for $30 \mathrm{~min}$. After this time, each sample was wrung out and left to dry in air for $2 \mathrm{~h}$. Typically, dilution ratios of CuNP stock solution equal to 1:100 and 1:1000 were used.

\subsection{Morphological and Spectroscopic Characterization}

Colloidal CuNPs diluted in the ratio 1:10 were sonicated for $30 \mathrm{~min}$, before Transmission Electron Microscopy (TEM) analysis, in order to prevent possible aggregation. TEM microscopy was performed with a FEI Tecnai 12 instrument (Hillsboro, OR, USA, high tension: $120 \mathrm{kV}$; filament: W), by dropping $10 \mu \mathrm{L}$ on carbon-coated $\mathrm{Cu}$ grids (300 mesh, TAAB Laboratories Equipment Ltd., Aldermaston, UK). The microscope was calibrated using the S106 Cross Grating (2160 lines/mm, $3.05 \mathrm{~mm}$ ) supplied by Agar Scientific (Stansted, UK). Alignment was checked by using factory settings and routines. Astigmatism was adjusted by means of fast Fourier transform processing. Size distribution of metal clusters was evaluated using ImageJ software [64]. Treated and pristine polyurethane materials were characterized by means of X-ray photoelectron spectroscopy (XPS), using a Thermo Fisher Scientific Theta Probe Spectrometer (Waltham, MA, USA). A monochromatized AlK $\alpha$ source was used, with a beam spot diameter of $300 \mu \mathrm{m}$. Samples were mounted onto the sample holder by means of a carbon double-side copper tape (Agar Scientific, Stansted, UK). All XPS measurements were performed in constant analyzer energy (CAE) mode. Survey and high-resolution spectra (C1s, $\mathrm{O} 1 \mathrm{~s}, \mathrm{Si} 2 \mathrm{p}, \mathrm{Cu} 2 \mathrm{p}_{3 / 2}, \mathrm{~N} 1 \mathrm{~s}, \mathrm{Ca} 2 \mathrm{p}$ and $\mathrm{Cl} 2 \mathrm{p}$ ) were acquired at a pass energy of 150 and $100 \mathrm{eV}$, respectively, and with a step size of 1.0 and $0.1 \mathrm{eV}$, respectively. Detailed spectra processing was performed by commercial Thermo Avantage software (v. 4.75@ 1999-2010 Thermo Fisher Scientific, Waltham, MA, 
USA). Curve-fitting analysis was applied to the $\mathrm{Cu} 2 \mathrm{p}_{3 / 2}$ high-resolution spectra, in order to assess $\mathrm{Cu}$ chemical state. Surface atomic percentages were determined after Shirley background removal, using Scofield sensitivity factors. The same peak lineshape parameters (Gaussian/Lorentzian ratio and full width at half maximum) values were employed for the curve fitting of components belonging to the same high-resolution spectrum. Spectra were corrected for charge compensation effects by offsetting the binding energy relative to the aliphatic component of the $\mathrm{C} 1 \mathrm{~s}$ spectrum, which was set to $284.8 \mathrm{eV}$.

\subsection{Kinetics of Copper Release in Aqueous Solution by Electro-Thermal Atomic Absorption Spectroscopy (ETAAS)}

Copper release from CuNP-modified polyurethane foams was evaluated by electro-thermal atomic absorption spectroscopy (ETAAS). Cu quantification was achieved by means of a calibration curve obtained by the analysis, carried out in triplicate and in random sequence, of standard solutions at known $\mathrm{Cu}$ concentration, prepared by subsequent dilution of a stock $\mathrm{Cu}$ commercial solution (Fluka, Milan, Italy, Copper Standard for AAS TraceCERT ${ }^{\circledR}, 1000 \mathrm{mg} / \mathrm{L} \mathrm{Cu}$ in nitric acid). Each PU sample was immersed in a Pyrex bottle containing $25 \mathrm{~mL}$ of contact solution. The latter was obtained as a 1:1 mixture of a $0.85 \% w / w \mathrm{NaCl}$ aqueous solution (Fluka, purity $\geqslant 99.5 \%$ ) with phosphate buffer (PBS) $\mathrm{K}_{2} \mathrm{HPO}_{4} / \mathrm{NaH}_{2} \mathrm{PO}_{4}$ with known $\mathrm{pH}$ and ionic strength (6.4 and 0.1, respectively). At fixed times (10 min, $1 \mathrm{~h}, 2 \mathrm{~h}, 4 \mathrm{~h}, 7 \mathrm{~h}, 10 \mathrm{~h}$ and $24 \mathrm{~h}$ ), $200 \mu \mathrm{L}$ of this solution were taken from each vessel. These samples were appropriately diluted and acidified by $0.7 \% \mathrm{HNO}_{3}$ solution; if needed, additional dilution was applied in order to keep the measured $\mathrm{Cu}$ concentration within the linearity interval of the calibration curve. Samples were analyzed by a Perkin-Elmer dual-beam spectrophotometer, model 460 (Milan, Italy), using electro-thermal atomization in graphite furnace. Source was a hollow-cathode lamp (absorption line at $324.7 \mathrm{~nm}$ ). The signal acquisition mode provided an automatic background correction by a deuterium lamp, in order to eliminate possible matrix absorption overlapping with the $\mathrm{Cu}$ absorption band. The entire kinetic experiment was carried out at $25^{\circ} \mathrm{C}$. The measured data were fitted by a first order kinetic Equation (1), where $[\mathrm{Cu}]^{0}$ represented the amount of copper ions immediately dissolved (and therefore immediately available) in solution, $[\mathrm{Cu}]^{\max }$ was the maximum copper concentration in solution reached within $24 \mathrm{~h}$, and $\mathrm{k}$ was the release kinetic constant. Data analysis was carried out using SigmaPlot ${ }^{\circledR} 12.0$ software (Systat Software, San Jose, CA, USA).

$$
[\mathrm{Cu}]=[\mathrm{Cu}]^{0}+[\mathrm{Cu}]^{\max }\left(1-\mathrm{e}^{-\mathrm{kt}}\right)
$$

The possible $\mathrm{Cu}$ release from both vessels/glassware and the untreated polyurethane foams was also assayed; and the resulting $\mathrm{Cu}$ concentrations were all below the limit of quantification (LOQ).

\subsection{Antimicrobial Tests}

Escherichia coli ATCC 25922, Staphylococcus aureus FDA 209P (MSSA, with methicillin resistance $0.125 \mu \mathrm{g} / \mathrm{mL}$ ), and Kluyveromyces marxianus CBS 608 were selected as target microorganisms. Aliquots of the different lyophilized microorganisms were reconstituted in $0.9 \% \mathrm{NaCl}$ solution, added to $20 \mathrm{~mL}$ of sterile nutrient broth (Oxoid) and incubated for $24 \mathrm{~h}$ at the optimal temperature for microbial growth, which was $37{ }^{\circ} \mathrm{C}$ for Staphylococcus aureus, $42{ }^{\circ} \mathrm{C}$ for Escherichia coli, and $28^{\circ} \mathrm{C}$ for Kluyveromyces marxianus. Each sample was then diluted $10^{5}$ times by saline solution $\left(\mathrm{pH}=6.4,\left[\mathrm{Cl}^{-}\right]=0.15 \mathrm{M}\right) .5 \mathrm{~mL}$ of each culture broth were left in contact with each type of CuNP treated foams, and incubated for $24 \mathrm{~h}$, at the respective optimal growth temperatures. Untreated samples were used as controls. After the selected incubation times, $1 \mathrm{~mL}$ of culture broth was taken from each vessel and inoculated in a Petri dish containing nutrient agar. After $24 \mathrm{~h}$, bacterial colony count was performed on each Petri dish, in order to assess the entity of bacterial growth inhibition exerted by treated polyurethane foams. 


\section{Conclusions}

Sacrificial-anode electrochemical synthesis of TOAC-stabilized CuNPs was used to modify industrial polyurethane foams. TEM and XPS analyses on Cu-nanocolloids demonstrated that the surfactant employed was capable of stabilizing freshly dispersed CuNPs from both the morphological and the chemical point of view. XPS measurements on copper-polyurethane composites revealed that a simple impregnation protocol employing diluted colloids was effective in modifying industrial polyurethane foams with CuNPs. These data, along with copper ion release measurements, showed that the final copper surface availability, along with the release of antibacterial ions in physiological solution, could be tuned just by changing the CuNP concentration in the impregnation baths. Foam pore size and aging resulted to affect the ion release to a minor extent, although samples stored for two months were demonstrated to be still very active in releasing bioactive copper ions. Biological tests showed that the proposed nano-functionalized materials exert a marked inhibitory effect on the growth of different target microorganisms such as S. aureus, E. coli and K. marxianus.

Acknowledgments: Lino Mondino, R \& D director of Adler Group, is gratefully acknowledged for technical discussions and for kindly providing samples of polyurethane foams. Leonardo Bellomo and Vito Scannicchio are acknowledged for partial contribution to the collection of some experimental data. Financial support from Italian MIUR (Project "Silver" PON01_02210) and from Regione Puglia (Project code 56: "Laboratorio di tecnologie di modificazione superficiale di fibre naturali per il rilancio del settore tessile in Puglia") is gratefully acknowledged.

Author Contributions: M.C.S. contributed to perform most of the experiments, and wrote the first draft of the paper. R.A.P. designed the experiments and analyzed the data. R.R. performed release experiments and contributed to other experimental activities. E.B. and G.T. performed antimicrobial tests. M.P., A.S., and A.V. contributed to materials characterization and to critical discussions. T.R.I.C. and N.C. supervised research activities and defined the final version of the manuscript. N.C. coordinated the project on Cu-modified polyurethanes. Authorship is limited to those who have contributed substantially to the work reported.

Conflicts of Interest: The authors declare no conflict of interest. The founding sponsors had no role in the design of the study; in the collection, analyses, or interpretation of data; in the writing of the manuscript, and in the decision to publish the results.

\section{Abbreviations}

The following abbreviations are used in this manuscript:

$\begin{array}{ll}\text { BE } & \text { binding energy } \\ \text { CFU } & \text { colony forming unit } \\ \text { CNT } & \text { carbon nanotube } \\ \text { CuNP } & \text { copper nanoparticle } \\ \text { ETAAS } & \text { electro-thermal atomic absorption spectroscopy } \\ \text { PBS } & \text { phosphate buffer saline } \\ \text { PU } & \text { polyurethane } \\ \text { SAE } & \text { sacrificial anode electrolysis } \\ \text { TEM } & \text { transmission electron microscopy } \\ \text { TOAC } & \text { tetraoctylammonium chloride } \\ \text { XPS } & \text { X-ray photoelectron spectroscopy }\end{array}$

\section{References}

1. Morent, R.; De Geyter, N. Improved textile functionality through surface modifications. In Functional Textiles for Improved Performance, Protection and Health; Pan, N., Sun, G., Eds.; Woodhead Publishing Series in Textiles; Woodhead Publishing: Cambridge, UK, 2011; pp. 3-26.

2. Gao, Y.; Cranston, R. Recent Advances in Antimicrobial Treatments of Textiles. Text. Res. J. 2008, 78, 60-72.

3. García, B.; Saiz-Poseu, J.; Gras-Charles, R.; Hernando, J.; Alibés, R.; Novio, F.; Sedó, J.; Busqué, F.; Ruiz-Molina, D. Mussel-Inspired Hydrophobic Coatings for Water-Repellent Textiles and Oil Removal. ACS Appl. Mater. Interfaces 2014, 6, 17616-17625. [CrossRef] [PubMed]

4. Onar, N.; Mete, G. Development of water-, oil-repellent and flame-retardant cotton fabrics by organic-inorganic hybrid materials. J. Text. Inst. 2016. [CrossRef] 
5. Badanova, A.K.; Kutzhanova, A.Z.; Krichevsky, G.E. Research of the influence of hydrophobic finishing on coloristic characteristics of cellulosic textile material. Izv. Vysshikh Uchebnykh Zaved. Seriya Teknol. Tekstil'noi Promyshlennosti 2015, 2015, 63-66.

6. Baltušnikaite, J.; Varnaite-Žuravliova, S.; Rubežiene, V.; Rimkute, R.; Verbiene, R. Influence of silver coated yarn distribution on electrical and shielding properties of flax woven fabrics. Fibres Text. East. Eur. 2014, 104, 84-90.

7. Hu, C.-C.; Chang, S.-S.; Liang, N.-Y. Preparation and characterization of carbon black/polybutylene terephthalate/polyethylene terephthalate antistatic fiber with sheath-core structure. J. Text. Inst. 2015. [CrossRef]

8. Baseri, S. Preparation and characterization of conductive and antibacterial polyacrylonitrile terpolymer yarns produced by one-step organic coating. J. Text. Inst. 2016. [CrossRef]

9. Patra, J.K.; Gouda, S. Application of nanotechnology in textile engineering: An overview. J. Eng. Technol. Res. 2013, 5, 104-111. [CrossRef]

10. Chandramohan, D.; Marimuthu, K. A review on natural fibers. Int. J. Res. Rev. Appl. Sci. 2011, 8, $194-206$.

11. Seves, A.; Romanò, M.; Maifreni, T.; Sora, S.; Ciferri, O. The microbial degradation of silk: A laboratory investigation. Int. Biodeterior. Biodegrad. 1998, 42, 203-211. [CrossRef]

12. Szostak-Kotowa, J. Biodeterioration of textiles. Int. Biodeterior. Biodegrad. 2004, 53, 165-170. [CrossRef]

13. Cioffi, N.; Rai, M. Nano-Antimicrobials: Progress and Prospects, 1st ed.; Springer: Berlin, Germany, 2012.

14. Giannossa, L.C.; Longano, D.; Ditaranto, N.; Nitti, M.A.; Paladini, F.; Pollini, M.; Rai, M.; Sannino, A.; Valentini, A.; Cioffi, N. Metal nanoantimicrobials for textile applications. Nanotechnol. Rev. 2013, 2, 307-331. [CrossRef]

15. Torres, A.; Ruales, C.; Pulgarin, C.; Aimable, A.; Bowen, P.; Sarria, V.; Kiwi, J. Innovative high-surface-area $\mathrm{CuO}$ pretreated cotton effective in bacterial inactivation under visible light. ACS Appl. Mater. Interfaces 2010, 2, 2547-2552. [CrossRef] [PubMed]

16. Teli, M.D.; Sheikh, J. Bamboo rayon-copper nanoparticle composites as durable antibacterial textile materials. Compos. Interfaces 2014, 21, 161-171. [CrossRef]

17. Subramanian, B.; Anu Priya, K.; Thanka Rajan, S.; Dhandapani, P.; Jayachandran, M. Antimicrobial activity of sputtered nanocrystalline $\mathrm{CuO}$ impregnated fabrics. Mater. Lett. 2014, 128, 1-4. [CrossRef]

18. Perelshtein, I.; Applerot, G.; Perkas, N.; Wehrschuetz-Sigl, E.; Hasmann, A.; Guebitz, G.; Gedanken, A. CuO-cotton nanocomposite: Formation, morphology, and antibacterial activity. Surf. Coat. Technol. 2009, 204, 54-57. [CrossRef]

19. Sedighi, A.; Montazer, M.; Samadi, N. Synthesis of nano $\mathrm{Cu}_{2} \mathrm{O}$ on cotton: Morphological, physical, biological and optical sensing characterizations. Carbohydr. Polym. 2014, 110, 489-498. [CrossRef] [PubMed]

20. Gouda, M.; Hebeish, A. Preparation and evaluation of $\mathrm{CuO} /$ Chitosan nanocomposite for antibacterial finishing cotton fabric. J. Ind. Text. 2010, 39, 203-214. [CrossRef]

21. Beddow, J.; Singh, G.; Blanes, M.; Molla, K.; Perelshtein, I.; Gedanken, A.; Joyce, E.; Mason, T. Sonochemical coating of textile fabrics with antibacterial nanoparticles. In AIP Conference Proceedings; AIP Publishing: Melville, NY, USA, 2012; pp. 400-403.

22. Anita, S.; Ramachandran, T.; Rajendran, R.; Koushik, C.V.; Mahalakshmi, M. A study of the antimicrobial property of encapsulated copper oxide nanoparticles on cotton fabric. Text. Res. J. 2011, 81, 1081-1088. [CrossRef]

23. Abramov, O.V.; Gedanken, A.; Koltypin, Y.; Perkas, N.; Perelshtein, I.; Joyce, E.; Mason, T.J. Pilot scale sonochemical coating of nanoparticles onto textiles to produce biocidal fabrics. Surf. Coat. Technol. 2009, 204, 718-722. [CrossRef]

24. Castro, C.; Sanjines, R.; Pulgarin, C.; Osorio, P.; Giraldo, S.A.; Kiwi, J. Structure-reactivity relations for DC-magnetron sputtered Cu-layers during E. coli inactivation in the dark and under light. J. Photochem. Photobiol. A Chem. 2010, 216, 295-302. [CrossRef]

25. Sedighi, A.; Montazer, M.; Hemmatinejad, N. Copper nanoparticles on bleached cotton fabric: In situ synthesis and characterization. Cellulose 2014, 21, 2119-2132. [CrossRef]

26. Gabbay, J. Copper oxide impregnated textiles with potent biocidal activities. J. Ind. Text. 2006, 35, 323-335. [CrossRef]

27. Borkow, G.; Gabbay, J. Putting copper into action: Copper-impregnated products with potent biocidal activities. FASEB J. 2004, 18, 1728-1730. [CrossRef] [PubMed] 
28. Borkow, G.; Gabbay, J. Copper, an ancient remedy returning to fight microbial, fungal and viral infections. Curr. Chem. Biol. 2009, 3, 272-278. [CrossRef]

29. Huang, Z.-M.; Zhang, Y.-Z.; Kotaki, M.; Ramakrishna, S. A review on polymer nanofibers by electrospinning and their applications in nanocomposites. Compos. Sci. Technol. 2003, 63, 2223-2253. [CrossRef]

30. Brzeziński, S.; Malinowska, G.; Kowalczyk, D.; Kaleta, A.; Boak, B.; Jasiorski, M.; Dabek, K.; Baszczuk, A.; Tracz, A. Antibacterial and fungicidal coating of textile-polymeric materials filled with bioactive nano- and submicro-particles. Fibers Text. East. Eur. 2012, 20, 70-77.

31. Mumcuoglu, K.Y.; Gabbay, J.; Borkow, G. Copper oxide-impregnated fabrics for the control of house dust mites. Int. J. Pest Manag. 2008, 54, 235-240. [CrossRef]

32. Rio, L.; Kusiak-Nejman, E.; Kiwi, J.; Bétrisey, B.; Pulgarin, C.; Trampuz, A.; Bizzini, A. Comparison of methods for evaluation of the bactericidal activity of copper-sputtered surfaces against methicillin-resistant Staphylococcus aureus. Appl. Environ. Microbiol. 2012, 78, 8176-8182. [CrossRef] [PubMed]

33. Komeily-Nia, Z.; Montazer, M.; Latifi, M. Synthesis of nano copper/nylon composite using ascorbic acid and CTAB. Colloids Surf. A Physicochem. Eng. Asp. 2013, 439, 167-175. [CrossRef]

34. Amina, M.; Amna, T.; Hassan, M.S.; Ibrahim, T.A.; Khil, M.-S. Facile single mode electrospinning way for fabrication of natural product based silver decorated polyurethane nanofibrous membranes: Prospective medicated bandages. Colloids Surf. A Physicochem. Eng. Asp. 2013, 425, 115-121. [CrossRef]

35. Tijing, L.D.; Ruelo, M.T.G.; Amarjargal, A.; Pant, H.R.; Park, C.-H.; Kim, C.S. One-step fabrication of antibacterial (silver nanoparticles/poly(ethylene oxide))-Polyurethane bicomponent hybrid nanofibrous mat by dual-spinneret electrospinning. Mater. Chem. Phys. 2012, 134, 557-561. [CrossRef]

36. Nirmala, R.; Kalpana, D.; Navamathavan, R.; Park, M.; Kim, H.Y.; Park, S.-J. Antimicrobial activity of electrospun polyurethane nanofibers containing composite materials. Korean J. Chem. Eng. 2014, 31, 855-860. [CrossRef]

37. Jeon, H.J.; Kim, J.S.; Kim, T.G.; Kim, J.H.; Yu, W.-R.; Youk, J.H. Preparation of poly(E-caprolactone)-based polyurethane nanofibers containing silver nanoparticles. Appl. Surf. Sci. 2008, 254, 5886-5890. [CrossRef]

38. Prabhakar, P.K.; Raj, S.; Anuradha, P.R.; Sawant, S.N.; Doble, M. Biocompatibility studies on polyaniline and polyaniline-silver nanoparticle coated polyurethane composite. Colloids Surf. B Biointerfaces 2011, 86, 146-153. [CrossRef] [PubMed]

39. Yang, Z.; Qiu, S.; Wang, Y.; Lv, H.; Xing, X.; Luo, J. Synthesis and characterization of re-dispersible silver nanoparticles/polyurethane hybrid materials. Polym. Mater. Sci. Eng. 2012, 28, 118-121.

40. Toker, R.D.; Kayaman-Apohan, N.; Kahraman, M.V. UV-curable nano-silver containing polyurethane based organic-inorganic hybrid coatings. Prog. Org. Coat. 2013, 76, 1243-1250. [CrossRef]

41. Pant, H.R.; Kim, H.J.; Joshi, M.K.; Pant, B.; Park, C.H.; Kim, J.I.; Hui, K.S.; Kim, C.S. One-step fabrication of multifunctional composite polyurethane spider-web-like nanofibrous membrane for water purification. J. Hazard. Mater. 2014, 264, 25-33. [CrossRef] [PubMed]

42. Kim, J.H.; Unnithan, A.R.; Kim, H.J.; Tiwari, A.P.; Park, C.H.; Kim, C.S. Electrospun badger (Meles meles) oil/Ag nanoparticle based anti-bacterial mats for biomedical applications. J. Ind. Eng. Chem. 2015, 30, 254-260. [CrossRef]

43. Dumitriu, R.P.; Sacarescu, L.; Macocinschi, D.; Filip, D.; Vasile, C. Effect of silver nanoparticles on the dispersion, rheological properties and morphological aspect of solvent cast polyurethane/biopolymers bionanocomposite membranes. J. Adhes. Sci. Technol. 2016, 30, 1716-1726. [CrossRef]

44. Wang, X.; Chen, M.-Q.; Chen, Q.-H.; Lu, J.; Cheng, L.; Jiang, H.; Dai, L.-F.; Zhang, H.-D.; Yang, T.-W.; Pei, Y.-H.; et al. Reduction of biofilm formation in rabbits by novel nano-silver/polyurethane coated endotracheal tube. J. Biomater. Tissue Eng. 2015, 5, 961-966. [CrossRef]

45. Subagia, I.D.G.A.; Jiang, Z.; Tijing, L.D.; Kim, Y.; Kim, C.S.; Lim, J.K.; Lim, J.K. Hybrid multi-scale basalt fiber-epoxy composite laminate reinforced with Electrospun polyurethane nanofibers containing carbon nanotubes. Fibers Polym. 2014, 15, 1295-1302. [CrossRef]

46. Shamshi Hassan, M.; Amna, T.; Sheikh, F.A.; Al-Deyab, S.S.; Eun Choi, K.; Hwang, I.H.; Khil, M.-S. Bimetallic $\mathrm{Zn} / \mathrm{Ag}$ doped polyurethane spider net composite nanofibers: A novel multipurpose electrospun mat. Ceram. Int. 2013, 39, 2503-2510. [CrossRef]

47. Tijing, L.D.; Ruelo, M.T.G.; Amarjargal, A.; Pant, H.R.; Park, C.-H.; Kim, D.W.; Kim, C.S. Antibacterial and superhydrophilic electrospun polyurethane nanocomposite fibers containing tourmaline nanoparticles. Chem. Eng. J. 2012, 197, 41-48. [CrossRef] 
48. Tijing, L.D.; Amarjargal, A.; Jiang, Z.; Ruelo, M.T.G.; Park, C.-H.; Pant, H.R.; Kim, D.-W.; Lee, D.H.; Kim, C.S. Antibacterial tourmaline nanoparticles/polyurethane hybrid mat decorated with silver nanoparticles prepared by electrospinning and UV photoreduction. Curr. Appl. Phys. 2013, 13, 205-210. [CrossRef]

49. Luo, Z.; Hong, R.Y.; Xie, H.D.; Feng, W.G. One-step synthesis of functional silica nanoparticles for reinforcement of polyurethane coatings. Powder Technol. 2012, 218, 23-30. [CrossRef]

50. Amna, T.; Hassan, M.S.; Sheikh, F.A.; Lee, H.K.; Seo, K.-S.; Yoon, D.; Hwang, I.H. Zinc oxide-doped poly(urethane) spider web nanofibrous scaffold via one-step electrospinning: A novel matrix for tissue engineering. Appl. Microbiol. Biotechnol. 2013, 97, 1725-1734. [CrossRef] [PubMed]

51. Sheikh, F.A.; Kanjwal, M.A.; Saran, S.; Chung, W.-J.; Kim, H. Polyurethane nanofibers containing copper nanoparticles as future materials. Appl. Surf. Sci. 2011, 257, 3020-3026. [CrossRef]

52. Tian, Q.; Guo, X. Electroless copper plating on microcellular polyurethane foam. Trans. Nonferrous Met. Soc. China 2010, 20, s283-s287. [CrossRef]

53. Nirmala, R.; Jeon, K.S.; Lim, B.H.; Navamathavan, R.; Kim, H.Y. Preparation and characterization of copper oxide particles incorporated polyurethane composite nanofibers by electrospinning. Ceram. Int. 2013, 39, 9651-9658. [CrossRef]

54. Reetz, M.T.; Helbig, W. Size-selective synthesis of nanostructured transition metal clusters. J. Am. Chem. Soc. 1994, 116, 7401-7402. [CrossRef]

55. Cioffi, N.; Torsi, L.; Sabbatini, L.; Zambonin, P.G.; Bleve-Zacheo, T. Electrosynthesis and characterisation of nanostructured palladium-polypyrrole composites. J. Electroanal. Chem. 2000, 488, 42-47. [CrossRef]

56. Ditaranto, N.; Picca, R.A.; Sportelli, M.C.; Sabbatini, L.; Cioffi, N. Surface characterization of manufactured goods modified by metal/metal oxides nano-antimicrobials. Surf. Interface Anal. 2016, 48, 505-508. [CrossRef]

57. Wagner, C.D. Handbook of X-ray Photoelectron Spectroscopy: A Reference Book of Standard Data for Use in X-ray Photoelectron Spectroscopy; Physical Electronics Division; Perkin-Elmer Corp.: Waltham, MA, USA, 1979.

58. NIST XPS Database. Available online: http:/ /www.srdata.nist.gov/xps (accessed on 5 July 2016).

59. Jirka, I. An ESCA study of copper clusters on carbon. Surf. Sci. 1990, 232, 307-315. [CrossRef]

60. Wu, Y.; Garfunkel, E.; Madey, T.E. Initial stages of $\mathrm{Cu}$ growth on ordered $\mathrm{Al}_{2} \mathrm{O}_{3}$ ultrathin films. J. Vac. Sci. Technol. A 1996, 14, 1662-1667. [CrossRef]

61. Cioffi, N.; Torsi, L.; Ditaranto, N.; Tantillo, G.; Ghibelli, L.; Sabbatini, L.; Bleve-Zacheo, T.; D'Alessio, M.; Zambonin, P.G.; Traversa, E. Copper Nanoparticle/Polymer Composites with Antifungal and Bacteriostatic Properties. Chem. Mater. 2005, 17, 5255-5262. [CrossRef]

62. Cioffi, N.; Torsi, L.; Ditaranto, N.; Sabbatini, L.; Zambonin, P.G.; Tantillo, G.; Ghibelli, L.; D'Alessio, M.; Bleve-Zacheo, T.; Traversa, E. Antifungal activity of polymer-based copper nanocomposite coatings. Appl. Phys. Lett. 2004, 85, 2417-2419. [CrossRef]

63. Cioffi, N.; Ditaranto, N.; Torsi, L.; Picca, R.A.; Giglio, E.D.; Sabbatini, L.; Novello, L.; Tantillo, G.; Bleve-Zacheo, T.; Zambonin, P.G. Synthesis, analytical characterization and bioactivity of Ag and Cu nanoparticles embedded in poly-vinyl-methyl-ketone films. Anal. Bioanal. Chem. 2005, 382, $1912-1918$. [CrossRef] [PubMed]

64. ImageJ. Available online: http://imagej.nih.gov/ij/ (accessed on 19 November 2015).

(C) 2016 by the authors; licensee MDPI, Basel, Switzerland. This article is an open access article distributed under the terms and conditions of the Creative Commons Attribution (CC-BY) license (http://creativecommons.org/licenses/by/4.0/). 